\title{
Caffeine in surface and wastewaters in Barbados, West Indies
}

\author{
Quincy A Edwards*', Sergei M Kulikov* and Leah D Garner-O’Neale
}

\begin{abstract}
Caffeine, a purine alkaloid drug, has been recognized as a contaminant of water bodies in various climatic regions, however, these environmental caffeine concentrations are the first to be reported in the tropical Caribbean. The major objective of this study was to develop an improved method to extract caffeine from surface and wastewaters in the warm Caribbean environment and measure caffeine concentrations in highly populated areas in Barbados. Caffeine was extracted from water via solid phase extraction (SPE); the acidified water samples were loaded onto C-18 cartridges and eluted with pure chloroform. The extracted caffeine was quantified using gas chromatography mass spectroscopy - multiple reaction monitoring (GC-MS/MS-MRM). Method detection limits of $0.2 \mathrm{ng} \mathrm{L}^{-1}$ from $1 \mathrm{~L}$ water samples were achieved. Caffeine was detected in all environmental water samples investigated. The concentrations of caffeine in surface waters were detected in the range $0.1-6.9 \mu \mathrm{g} \mathrm{L}^{-1}$. The two wastewater treatment plants, primary and secondary treatment systems, significantly differed in their ability to eliminate caffeine in the raw sewage (38\% and $99 \%$ caffeine removal efficiencies respectively). Thus, it may be essential to employ secondary treatment to effectively remove caffeine from wastewater systems in Barbados. Caffeine in water bodies are principally attributed to anthropogenic sources as caffeine-producing plants are not commonly grown on the island of Barbados. The study also shows the recalcitrance of caffeine to hydrolytic degradation.
\end{abstract}

Keywords: Barbados; Caffeine; Contamination; Surface water; Wastewater

\section{Introduction}

Caffeine is one of the most widely consumed psychoactive substances in the world as it is consumed daily in coffee, tea, soft drinks and chocolate (Ferreira 2005). It is also an ingredient in condiments, tobacco and medications. Caffeine is popularly consumed as it is a stimulant of the central nervous system which has the effect of temporarily rejuvenating the body and restoring alertness (Ferreira 2005). The global average consumption of caffeine is estimated to be generally between 80 and $400 \mathrm{mg}$ per person per day (Gokulakrishnan et al. 2005), but the average caffeine intake per person per day values for Switzerland, the United Kingdom and the United States of America are estimated at $300 \mathrm{mg}, 440 \mathrm{mg}$ and $210 \mathrm{mg}$ respectively (Buerge et al. 2003; Standley et al. 2002). In humans caffeine is rapidly metabolized by the liver and the majority of the ingested caffeine is converted

\footnotetext{
*Correspondence: quincy.edwards@mycavehill.uwi.edu; sergei.kulikov@cavehill.uwi.edu

Department of Biological and Chemical Sciences, The University of the West Indies, Cave Hill Campus, PO BOX 64 Bridgetown, West Indies, Barbados
}

to one or more secondary metabolites. Thus, about $0.5 \%$ to $10 \%$ is excreted through urine and faeces (Seiler et al. 1999; Berthou et al. 1992; Knee et al. 2010; Rodriguez del Rey et al. 2012).

Although it is found in many types of plants, the presence of caffeine in environmental waters is largely attributed to discharges of domestic wastewater (Martín et al. 2012; Metcalfe et al. 2003; Seiler et al. 1999; Wu et al. 2010). On the island of Barbados caffeine plants are not commonly grown, moreover, few cocoa and coffee plants are found in botanical gardens. Some researchers have found that anthropogenic caffeine is transported to ponds and marine systems via streams and rivers draining to the coast. Other researchers have indicated that overflows of on-site wastewater treatment systems and storm water run-off are also contributors of caffeine to surface waters. (Buerge et al. 2006; Peeler et al. 2006; Rounds et al. 2009). However, a significant source of caffeine to domestic wastewater is likely to be the disposal of unconsumed coffee, tea or soft drinks down household drains and rinsing of coffee pots and cups. The disposal of even a few cups of

\section{实}


coffee into household drainage systems could contribute to hundreds of milligrams of caffeine to surface waters as domestic wastewater from sinks may flow to streams, rivers or ponds that finally deposits into the marine environment (Seiler et al. 1999). Another anthropogenic source of caffeine to the environment that is commonly neglected is the direct disposal of leftover medications into household sinks, toilets, or in trash that end up at the landfill. Caffeine tracked the population density and elevated concentrations of caffeine were attributed to large populations (Peeler et al. 2006; Rodriguez del Rey et al. 2012).

Caffeine has several unique characteristics important for a good chemical marker of pollution. It is highly soluble in water $\left(13 \mathrm{~g} \mathrm{~L}^{-1}\right)$ having a very low octanol-water coefficient $\left(\log \mathrm{k}_{\mathrm{ow}}=-0.07\right)$, insignificant volatility and its half-life is about 10 years (Buerge et al. 2006; Lin et al. 2009; Froehner and Martins 2008; Chen et al. 2012). Kurissery et al. 2012 found that the concentration of caffeine did not show any significant correlation with hydrologic parameters such as surface water temperature, $\mathrm{pH}$ or dissolved oxygen indicating its stability and slow pace of degradation. It fits the profile for a good marker directly related to anthropogenic influences with no potential biogenic sources (Siegener and Chen 2002). However, researchers have proved that caffeine is readily biodegradable (Thomas and Foster 2005; Gómez et al. 2007).

Bacterial strains belonging to Pseudomonas, Serratia, and fungal strains of Aspergillus, Penicillium, Phanerochaete, Rhizopus, and Stemphylium are reported to degrade caffeine (Yu et al. 2009; Beltrán et al. 2006; Asano et al. 1993; Dash and Gummadi 2007; Yamaoka-Yano and Mazzafera 1999). Dash and Gummadi 2006 found that Pseudomonas is the best organism for caffeine degradation with Pseudomonas sp. NCIM 5235 showing complete degradation of $6.4 \mathrm{~g} \mathrm{~L}^{-1}$ of caffeine in 24 hours. Wastewater treatment plants (WWTPs) elimination of caffeine $(81-100 \%)$ have been found to be more profound when secondary treatment (e.g. biological treatment) is employed (Buerge et al. 2006; Lin et al. 2009, Siegener and Chen 2002; Benotti and Brownawell 2007). Removal efficiency diminishes considerably in WWTPs using less advanced treatment processes (Rodriguez del Rey et al. 2012). For example, Boisvert et al. 2012 reported a removal efficiency of $<10 \%$ using primary treatment in Canada.

Caffeine may also be a pollutant to marine ecosystems. A study by Pollack et al. 2009 suggested that exposure to caffeine may exacerbate the effects of other environmental parameters on coral such as changes in ocean temperatures and $\mathrm{pH}$, making them more likely to undergo bleaching. Coral reef ecosystems are major aesthetic attractions in the Caribbean region and thus the sustainability of coral reefs in the region is important to our eco-tourism industry.
The study was instigated due to a lack of data on emerging contaminants in environmental waters in the Caribbean region. Based on our knowledge this investigation of caffeine or pharmaceuticals in surface and wastewater is the first to be conducted in the West Indies and may help to foster more research on emerging contaminants in the said region in the near future. Furthermore, in this part of the world there are no legislative guidelines associated with these contaminants in natural waters hence this research may help in the development of standards and regulatory testing of these compounds in our natural waters.

The primary aim of this work was the development of an integral methodology to determine the concentration of caffeine in surface and wastewater and evaluate the removal efficiencies of caffeine in two WWTPs in Barbados. These data are compared to results collected around the world. The secondary aims of the paper are to evaluate the sources of caffeine in surface water, whether natural or anthropogenic and assess the stability of caffeine in aqueous solutions.

\section{Materials and methods \\ Site description}

Both surface water and wastewater samples were collected during December 2012. The local mean temperature of December was $27^{\circ} \mathrm{C}$. Barbados is 166 sq. miles $\left(432 \mathrm{~km}^{2}\right)$ and has a population of approximately 300,000 people. For this study four highly populated areas were selected for surface water sampling that represented both land drainage and various levels of anthropogenic influences including household, commercial businesses, and agriculture. These sites included Brandon's Beach Catch-

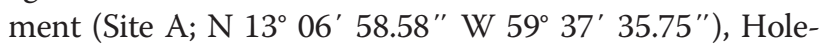

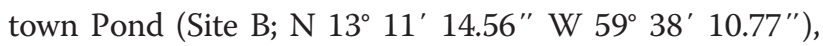
Pelican Village Drainage (Site C; $13^{\circ} 05^{\prime} 52.70^{\prime \prime}$ W $59^{\circ} 37^{\prime}$ 25.42") and Queen's Park Constitution River (Site D; N $\left.13^{\circ} 05^{\prime} 55.10^{\prime \prime} \mathrm{W} 59^{\circ} 36^{\prime} 27.60^{\prime \prime}\right)$. Sites C and D are located in the capital city, Bridgetown in the parish of St. Michael, which inhabits about 120,000 people (7,300/sq. mile). Site A is also located in the parish of St. Michael but in a small urban area outside of Bridgetown inhabiting approximately 5,000 people (3,100/sq.mile). Site B is located in the town of the parish of St. James that has a population of about 30,000 people (2,400/sq.mile). The Holetown Pond, Site B, is a large body of water of approximately 80,000 gallons. All the surface water sites were fairly transparent and flowing with exception to site A which was stagnant, of green colour and a foul odour. All surface water runoffs are finally deposited at sea. Figure 1 shows a map of Barbados highlighting sampling sites in specific parishes.

Wastewater samples (both influent and effluent) were collected from the wastewater treatment plants (WWTPs) 


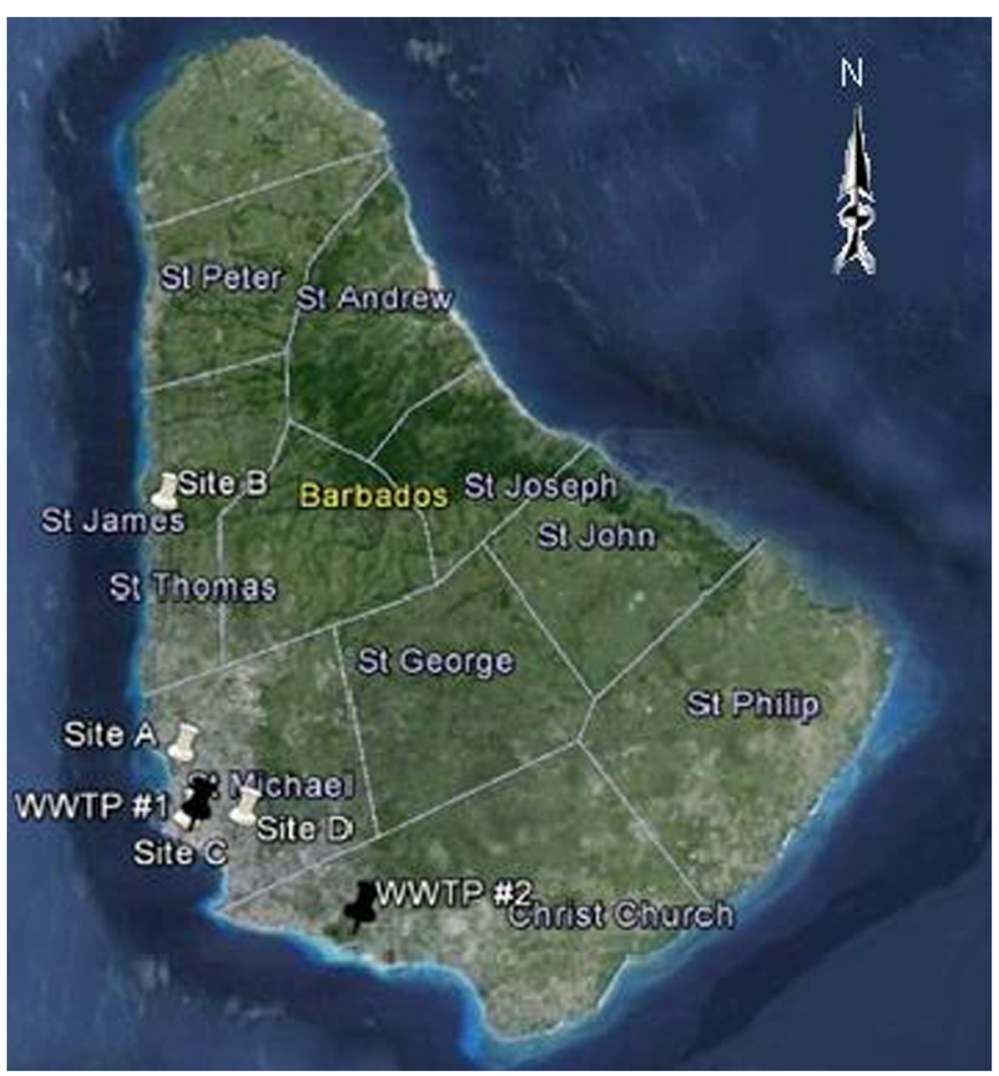

Figure 1 Sampling sites in Barbados. Black and white placemarks represent WWTPs and surface water sites respectively.

located in Bridgetown $\left(9,500-11,300 \mathrm{~m}^{3} / \mathrm{d}\right.$, mainly commercial connections) and the South Coast (2,600 $3,800 \mathrm{~m}^{3} / \mathrm{d}$, mainly residential connections) of Barbados and analyzed for the target compound. The former plant, WWTP \# 1 (N 13 $06^{\prime} 01.88^{\prime \prime}$ W $\left.59^{\circ} 37^{\prime} 15.63^{\prime \prime}\right)$, is a secondary treatment plant serving community of Bridgetown (which is densely populated with a high concentration of local and commercial businesses) and other areas. The latter, WWTP \# 2 (N 13 04' 20.64" W $59^{\circ} 34^{\prime} 22.97^{\prime \prime}$ ), is a primary treatment plant also located in a highly populated area; however, the South Coast (Christ Church; 50,000 people, 2,500/sq.mil) is a tourist "hotspot" because of the abundance of hotels and night entertainment in that district. Domestic waste from hotels in the South Coast area is transported to WWTP \# 2. The tourist season in Barbados extends from the month of December to April. Treated wastewater is also deposited at sea.

\section{Chemicals and materials}

Natural caffeine 99.9\% (Reagent Plus), chloroform (Chromaslov for HPLC), hydrochloric acid $(\mathrm{HCl})$, methanol (Chromasolv) and sodium hydroxide $(\mathrm{NaOH})$ were purchased from Sigma Aldrich (St. Louis, MO, USA). The internal standard 1,4-dichloro-benzene was obtained from BDH Laboratory (Poole, England). A stock solution of the standard was prepared separately in methanol at a concentration of $100 \mathrm{mg} \mathrm{L}^{-1}$. The stock solution was kept in the dark at $4^{\circ} \mathrm{C}$. Caffeine surrogate internal standard (purity $99 \%{ }^{13} \mathrm{C}_{3}$-labelled, $100 \mu \mathrm{g} \mathrm{mL}{ }^{-1}$ ) was later obtained from Cambridge Isotope Laboratories Inc. (Andover, MA, USA). Solid phase extraction cartridges used for sample preparation included Strata X (C-18 styrenedivinylbenzene polymer sorbent) cartridges $(2 \mathrm{~g})$ purchased from Phenomenex (Torrance, CA, USA). High Purity water (Sigma Aldrich, USA) was used for all experiments.

\section{Sampling and sample preparation}

Grab water samples $(1.2 \mathrm{~L})$ were collected in 2012 from surface water and wastewater (both influent and effluent) sites during the dry season in highly populated areas in Barbados. Water samples were collected in amber glass bottles which were previously cleaned in the laboratory as followed: soap cleaned, rinsed five times with tap water, soaked in 10\% hydrochloric acid for 1 hour, rinsed five times with distilled water and rinsed three times with methanol to remove any organic contamination. Each amber bottle was rinsed with sample water on the site immediately prior to collection. Samples were stored on ice $\left(\sim 4^{\circ} \mathrm{C}\right)$ and extracted within 24 hours. 
Samples collected with sediments or algae were first centrifuged with a Beckman Centrifuge J2 MC (10,000 rpm at $25^{\circ} \mathrm{C}$ for 15 minutes) and then filtered via paper filtration under suction. Water samples $(1 \mathrm{~L})$ were acidified to $\mathrm{pH} 2$ using $\mathrm{HCl}\left(1 \mathrm{Mol}^{-1}\right)$ and caffeine extracted via SPE Strata $\mathrm{X}$ cartridges. An improved SPE method was developed for the extraction of caffeine from natural water. The solid phase was conditioned with $15 \mathrm{~mL}$ of methanol followed by $30 \mathrm{~mL}$ of purified water adjusted to $\mathrm{pH} 2$. Samples were passed through the cartridges at a flow rate of approximately $5 \mathrm{~mL} \mathrm{~min}^{-1}$. All sample bottles were rinsed three times with $10 \mathrm{~mL}$ of $\mathrm{pH} 2$ purified water and the rinses were combined and passed through the SPE cartridge. The cartridge (sorbent) was then dried for 15 minutes under vacuum.

The caffeine analyte was eluted twice with two $50 \mathrm{~mL}$ portions of chloroform under vacuum at a flow rate

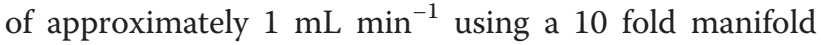
(Phenomenex, Torrance, CA, USA). After elution the cartridges were dried for 15 minutes. The solvent was immediately evaporated to dryness using a rotavapor rotary evaporator (Buchi Labortechnik AG, Switzerland; model RE-121) and reconstituted to a final volume of $1 \mathrm{~mL}$ in methanol and stored in amber vials. Reconstituted samples were stored in the refrigerator until analysis. Procedural blanks were run periodically to check for caffeine contamination during extraction. Recovery tests were made using purified water with caffeine concentrations of 0.5 and $1 \mu \mathrm{g} \mathrm{L}^{-1}$.

\section{Chromatographic analysis}

A known concentration of internal standard, 1,4-dichlorobenzene, was added to the sample prior to GC-MS analysis. Aliquots of $1 \mu \mathrm{L}$, using an Agilent Technologies 7693 autosampler, of the final extracts were analyzed by gas chromatography coupled with mass spectroscopy (GC-MS) on an Agilent 7000A GC-MS triple quad model (USA). The extracts were injected in the splitless mode with the injector port temperature at $280^{\circ} \mathrm{C}$. A $30 \mathrm{~m} \times 0.25 \mathrm{~mm}$ i.d. DB-5MS (5\% phenyl, 95\% methylpolysiloxane) capillary column (Agilent, USA) with a $0.25 \mu \mathrm{m}$ film thickness was used. Helium was used as the carrier gas at a constant flow of $1.2 \mathrm{~mL} \mathrm{~min}{ }^{-1}$. The column temperature program for the $\mathrm{GC}$ oven was as follows: initial temperature $70^{\circ} \mathrm{C}$, maintained for $2 \mathrm{mi}-$ nutes and then ramped at $20^{\circ} \mathrm{C}$ to $230^{\circ} \mathrm{C}$, where it was held for 4 minutes. Total run time was 10 minutes.

The mass spectrometer with electron impact ionization at 70 electron volt $(\mathrm{eV})$ and $25 \mathrm{eV}$ in the first and second ionization chambers respectively was operated in multiple reaction monitoring (MRM) mode. The interface as well as the spectrometer transfer line temperature was maintained at $280^{\circ} \mathrm{C}$. The peaks produced by caffeine and 1,4-dichlorobenzene were used to quantify natural caffeine. A multi-point calibration curve of peak area ratio (analyte to standard peak area) against analyte concentration was used to quantify the unknown concentration of the caffeine in field samples. The instrumental detection limit (LOD) and quantification limit (LOQ) were defined as the lowest analyte concentration that produced a peak with signal-to-noise ratio of 3 and 10 respectively (Li et al. 2010).

\section{Caffeine decomposition in aqueous solutions}

The reaction kinetics was monitored by following the decomposition of caffeine in aqueous solutions over a variety of temperature and $\mathrm{pH}$. Caffeine concentration was measured by GC-MS/MS-MRM as described above; however, standard addition of ${ }^{13} \mathrm{C}_{3}$-labeled caffeine was added to the prepared sample prior to analysis. Reactions were carried out in a $250 \mathrm{~mL}$ glass reaction vessel with a water cool condenser at $100^{\circ} \mathrm{C}$ (boiling), unless stated otherwise. Caffeine solution $(100 \mathrm{~mL})$ of initial concentration of $25 \mathrm{mg} \mathrm{L}^{-1}$ was placed into the glass vessel; during the course of the reaction aliquots of the solution $(2 \mathrm{~mL})$ were taken and fast cooled with icewater mixture. One millilitre of the cooled aliquot was diluted in methanol to give an initial $1 \mathrm{mg} \mathrm{L}^{-1}$ caffeine concentration at time zero. Experimental time varied from minutes to hours for acidic, neutral and basic solutions. Caffeine thermal decomposition reactions of temperatures $70-90^{\circ} \mathrm{C}$ were conducted in a Precision Thermo Scientific Oven (model 25 EM) that was preheated for 1 hour.

\section{Results and discussion}

\section{Occurrence of caffeine in surface water}

An improved SPE method was developed for the extraction of caffeine from water. Principally, chloroform was used for the elution of caffeine from the C-18 cartridge sorbent as opposed to a combination of $\mathrm{MeOH}$ and methylene chloride or methyl tert-butyl ether (MTBE) and $\mathrm{MeOH}$ used in earlier studies (Peeler et al. 2006; Verenitch and Mazumder 2008). Recovery tests showed that the developed SPE method was very effective (95$100 \%$ ) in extracting caffeine from pure water, reported in Table 1. Solubility studies have found that caffeine is about twice as soluble in chloroform as opposed to methylene chloride and about one order of magnitude more soluble in chloroform than methanol at temperatures $27-32^{\circ} \mathrm{C}$ and thus chloroform should be an effective solvent to separate caffeine from solutions (Shalmashi and Golmohammad 2010). Dichlorobenzene was used as an internal standard in combination with external calibration due to the initial unavailability of ${ }^{13} \mathrm{C}_{3}$ caffeine surrogate. Since this internal standard was only added prior to GC-MS analysis, this compound did not correct for extraction efficiencies, but was used 
Table 1 Target compound and internal standards GC-MS and analytical parameters; chemical formulas, the chromatographic retention times, the mass spectrometric multiple reaction monitoring (MRM) ion transitions, external standard calibration linearity, the limits of detection (LOD) and quantification (LOQ) and percentage recovery of the analyte

\begin{tabular}{|c|c|c|c|c|c|c|c|}
\hline Compound & Chemical formula & Retention time (min) & MRM transition & Linearity $\left(\mathrm{R}^{2}\right)^{\mathrm{a}}$ & $\operatorname{LOD}\left(\mathrm{ng} \mathrm{L}^{-1}\right)$ & LOQ (ng L $\left.{ }^{-1}\right)$ & Recovery (\%) \\
\hline Caffeine & $\mathrm{C}_{8} \mathrm{H}_{10} \mathrm{~N}_{4} \mathrm{O}_{2}$ & 8.4 & $194 \longrightarrow 109$ & $0.999(7)$ & 0.2 & 1.0 & $95-100$ \\
\hline Dichlorobenzene & $\mathrm{C}_{6} \mathrm{H}_{4} \mathrm{Cl}_{2}$ & 4.2 & $146 \longrightarrow 111$ & - & - & - & - \\
\hline${ }^{13} C_{3}$ Caffeine & $\mathrm{C}_{8} \mathrm{H}_{10} \mathrm{~N}_{4} \mathrm{O}_{2}$ & 8.4 & $197 \longrightarrow 111$ & - & - & - & - \\
\hline
\end{tabular}

${ }^{a}$ Number of points used for linear regression is in parenthesis.

a Linear range $0.1-50 \mu \mathrm{g} \mathrm{L}^{-1}$.

as an indicator for instrument sensitivity and corrected for sample injection problems. Table 1 below shows the analytical parameters for the target compound.

On the Caribbean island of Barbados caffeine-producing plants are rarely grown. Private conversations with local agronomists and botanists at the University of the West Indies revealed that only a few caffeine-producing plants are grown on the Island (cocoa and coffee plants) and the majority is housed in botanical gardens. Furthermore, caffeine plants were nowhere in sight during surface water sampling. Thus, caffeine levels in water bodies may principally be attributed to anthropogenic sources. Caffeine was found in all surface water sites investigated during the beginning (December) of the tourist season, and ranged from 0.1-6.9 $\mu \mathrm{g} \mathrm{L}^{-1}$, shown in Table 2.

The average caffeine concentration at Site $\mathrm{D}$ was the highest (about 70 times greater than Site A) among the surface water sites investigated. This may be attributed to the fact that Site D is located in the "heart" of the capital city of Barbados (Bridgetown) which is the most densely populated area among the sites studied. Also, this river is in close proximity to densely populated residential areas and small business (e.g. convenient shops) that may be a non-point source of caffeine contamination as municipal wastes from sinks may be indirectly deposited into the river which drains into the marine environment. According to United States Environmental Protection Agency (US EPA) caffeine in domestic wastewater may be as a result of unconsumed coffee, tea or soft drinks disposed down household drains which may contribute to high concentrations of caffeine in surface water. Faulty septic systems and the disposal of medications into household sinks, toilets and trash are also relevant sources of caffeine to surface water. Furthermore,

Table 2 Mean $(n=3 ; \pm S D)$ concentrations $\left(\mu \mathrm{g} \mathrm{L}^{-1}\right)$ of caffeine in surface waters collected in Barbados

\begin{tabular}{ll}
\hline Locations & Caffeine $\left(\boldsymbol{\mu g} \mathbf{~ L}^{-1}\right)$ \\
\hline Site A: Brandon's Beach Catchment & $0.1 \pm 0.01$ \\
Site B: Holetown Pond & $0.5 \pm 0.04$ \\
Site C: Pelican Village Drainage & $0.4 \pm 0.04$ \\
Site D: Queen's Park Constitution River & $6.9 \pm 0.8$ \\
\hline
\end{tabular}

several researchers reported that caffeine concentrations in surface water positively correlated to the population density (Rodriguez del Rey et al. 2012; Martín et al. 2012; Froehner et al. 2010, Wu et al. 2010; Seiler et al. 1999).

Site C (a drainage stream) is also located in Bridgetown but at a different location that less transverse residential area. Proximal to site $\mathrm{C}$ are a few souvenir shops and small restaurants and bars that cater to cruise ship passengers as the ferry port is in walking distance. Thus, its location may contribute to the low (about 17 times less than site D) caffeine concentration found in this drainage stream or due to dilution, biodegradation or photodegradation. The caffeine levels at site B and C were similar, however, Site B is a surface water pond (approximately 80,000 gallons of water) located in the town of St. James which is the second most populated area examined. Thus, the caffeine concentration at Site B is highly diluted in comparison to site $\mathrm{C}$. The pond is located in an upscale business community which is a tourist "hot spot" in Barbados. It is located in walking distance to the popular malls, cinema and night clubs. Therefore, the pond may potentially be exposed to caffeine from sodas or energy drinks sold at the cinema and night clubs or residential housing and commercial businesses run-offs via drainage pipes or during heavy rainfall. According to Rodriguez del Rey et al. 2012, storm water run-off maybe a source of caffeine to water bodies. Rounds et al. 2009, cautioned that caffeine might be present in streams as a result of people discarding beverages (e.g. coffee, sodas etc.) in the street. Thus, storm water could represent a significant source of caffeine to environmental waters.

Site A, the least populated area, was found to have the least caffeine (approximately 70 times less than Site D). This domestic wastewater stream catchment is located in a populated urban area outside of Bridgetown but within the St. Michael Parish. The drainage stream traverses a populated residential area and it is in close proximity to fast food restaurants and local pharmacies which are potential sources of caffeinated products. However, the water at this catchment was stagnant, notably had an unpleasant smell and with an abundance of algae, characterized by the green colour of the water sample. In contrast, the water samples collected at the other surface 
water sites were fairly transparent and flowing. The low caffeine concentration in the catchment is likely due to biological activities and solar degradation of caffeine. Biological degradation within a water system is dependent on many factors such as microbial activity, temperature, trophic conditions and water depth (Buerge et al. 2003). The wastewater in the catchment was shallow and since the typical atmospheric temperature in Barbados ranged from $26-29^{\circ} \mathrm{C}$, biological decomposition along with solar degradation are likely to destroy the caffeine present in the Brandon's Beach Catchment. Several bacteria (e.g. Serratia and Pseudomonas), fungi (e.g. Aspergillus, Penicillium, Stemphylium) and algae (e.g. Symbiodinium clades: Aiptasia and Pseudoterogorgia) have been found to utilize caffeine as a carbon source (Pollack et al. 2009; Yu et al. 2009; Beltrán et al. 2006; Asano et al. 1993; Dash and Gummadi 2007; Yamaoka-Yano and Mazzafera 1999). All surface water sites investigated drains into the ocean. Thus, caffeine in the marine environment may also increase the population of microbes in seawater.

It was interesting to observe that the average caffeine concentration $\left(6.9 \mu \mathrm{g} \mathrm{L}^{-1}\right)$ at Site $\mathrm{D}$ was notably the highest concentration found in surface water when compared to literature findings. In most cases it was two to four times greater than surface water sites worldwide (Figure 2). In addition, the caffeine concentration at Site D exceeded that of raw sewage found in Canada, Korea, Spain and Thailand (Figure 3). This could be attributed to the fact that the volume of water at site $\mathrm{D}$ is relatively low (less diluted) as compared to the international sites mentioned. Importantly, the average caffeine concentration in surface water in Barbados based on the four sites investigated is about $2 \mu \mathrm{g} \mathrm{L}{ }^{-1}$ as shown in Figure 2. The average caffeine concentration is similar to that of
Germany. The preliminary results of this study may suggest that caffeine in surface water in Barbados relates to the population density as greater levels of caffeine in surface water are found in the more populated areas that may originate from anthropogenic sources.

To date no conclusive study has been done on caffeine as a contaminant and based on our knowledge there are no established guidelines for caffeine concentrations in environmental waters. However, the United States Food and Drug Association (U.S. FDA) requires environmental risk assessments of pharmaceutical compounds if predicted introductory concentrations are expected to be greater than $1 \mu \mathrm{g} \mathrm{L}^{-1}$ (United States Federal Drug Administration 1998). In contrast, the European Union (EU) mandates environmental risk assessment of all pharmaceutical substances with a predicted environmental concentration (PEC) of $0.01 \mu \mathrm{g} \mathrm{L}^{-1}$ (O'Brien and Dietrich 2004). The caffeine concentration found in Queen's Park Constitution River (Site D) is about seven (7) times and two orders magnitude greater than the U.S. FDA and EU PEC limits respectively for pharmaceutical compounds in environmental water and should be a "cause for concern" as the river drains to the marine environment. Literature findings have found caffeine in coastal waters ranging between 0.001-5 $\mu \mathrm{g} \mathrm{L}^{-1}$. Furthermore, caffeine in seawater has only recently being recognized of having potential effects on marine ecosystems. In one of the only studies to investigate the effect of caffeine on coral reefs, Pollack et al. 2009 alerted that caffeine may increase the effects of other environmental factors on corals and making them more susceptible to bleaching. Barbados, the Caribbean region, is known for its vibrant marine eco-tourism (e.g. scuba diving, submarine tours etc.) and lucrative fishing industry. Moreover, many individuals are employed in this

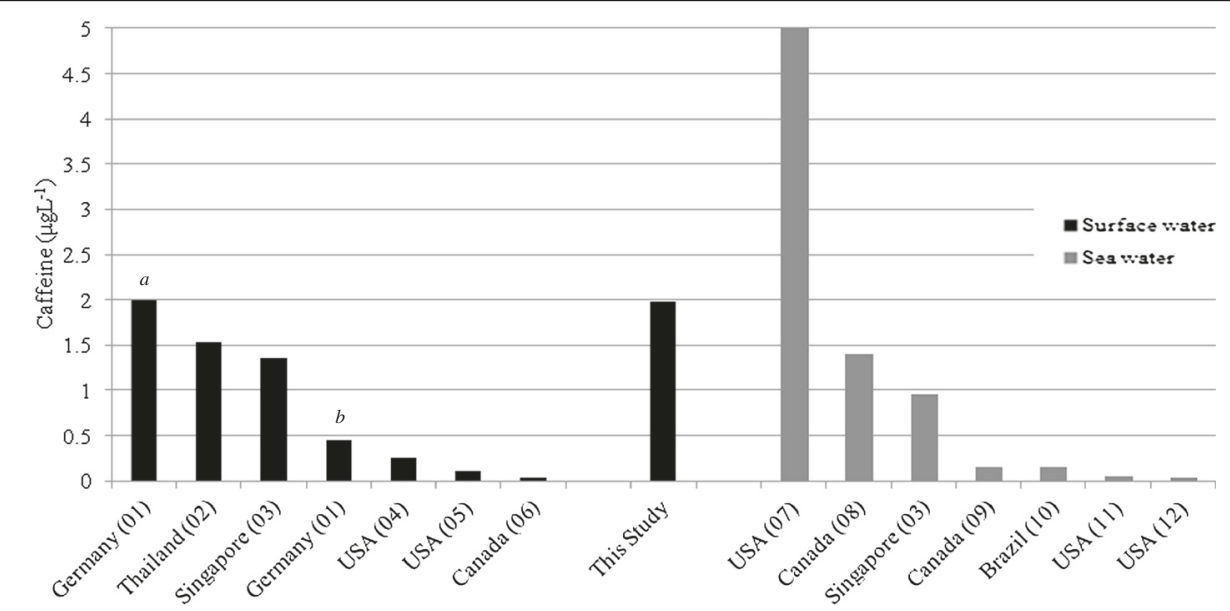

Figure 2 Selected average concentrations of caffeine in surface waters collected worldwide. Letters in italics represent locations proximal to wastewater plants: $a$ downstream, $b$ upstream. Numbers in parentheses are the following references: 01 Bahlmann et al. 2012, 02 Tewari et al. 2013, 03 Wu et al. 2010, 04 Siegener and Chen 2002, 05 Knee et al. 2010, 06 Yargeau et al. 2007, 07 Benotti and Brownawell 2007, 08 Comeau et al. 2008, 09 Verenitch and Mazumder 2008, 10 Ferreira 2005, 11 Rodriguez del Rey et al. 2012, 12 Singh et al. 2010. 


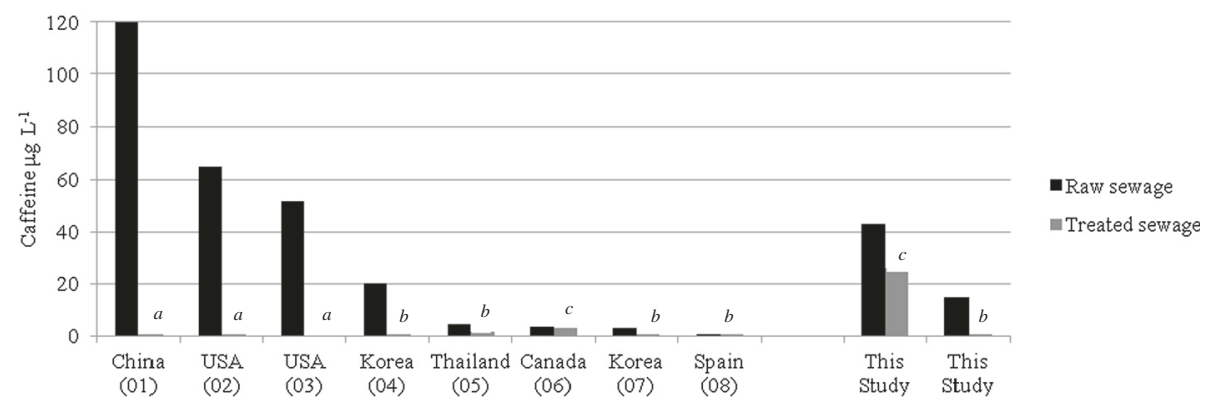

Figure 3 Selected average concentrations of caffeine in wastewater samples collected worldwide. Letters in italics are the following types of wastewater treatment effluents: $a$ tertiary, $b$ secondary, $c$ primary. Numbers in parentheses are the following references: 01 Yang et al. 2011,02 Trenholm et al. 2006, 03 Karnjanapiboonwong et al. 2011, 04 Sim et al. 2011, 05 Tewari et al. 2013, 06 Boisvert et al. 2012, 07 Behera et al. 2011, 08 Martín et al. 2012

fishing industry and thus healthy coral reefs are essential in maintaining the livelihood of these individuals in the region. It is of utmost importance for the region to monitor caffeine and other contaminants in surface water and the marine environment.

\section{Occurrence of caffeine in WWTPs}

As expected the caffeine concentrations in raw sewage was much greater than that found in surface waters in Barbados. The concentration of caffeine varied at both wastewater treatment facilities with the South Coast plant (WWTP 2) having higher concentrations of caffeine (about three times more caffeine) than the Bridgetown plant (WWTP 1) as shown in Table 3.

The WWTP 1 was found to be very effective in eliminating caffeine (99\% efficiency). On the other hand, the WWTP 2 was not as effective (38\% efficiency). The difference in the caffeine removal efficiencies at each wastewater plant could largely be due to the fact that the Bridgetown wastewater plant is a secondary treatment plant (removing all suspended and dissolved solids by combining them with activated sludge) whereas the South Coast wastewater plant is a primary treatment system (aeration and filtration). Thus, the Bridgetown plant is essentially the only system of the two that treats the wastewater, hence the significant difference in effluent quality. In addition, the South Coast sewage treatment

Table 3 Mean $(n=3 ; \pm S D)$ concentrations $\left(\mu \mathrm{g} \mathrm{L}^{-1}\right)$ of caffeine in wastewater collected from WWTPs that serve Barbadian communities

\begin{tabular}{lll}
\hline Wastewater treatment plants & Caffeine $\left(\boldsymbol{\mu \mathbf { g ~ L } ^ { - 1 } )}\right.$ & Efficiency $(\%)$ \\
\hline 1: Bridgetown & \\
Influent & $15 \pm 1.2$ & 99 \\
Effluent & $0.1 \pm 0.01$ & \\
2: South Coast & \\
Influent & $43 \pm 2.9$ & 38 \\
Effluent & $26 \pm 1.3$ & \\
\hline
\end{tabular}

plant (STP) serves commercial enterprises (hotels etc.) with approximately four thousand $(4,000)$ connections but the majority of waste received is residential. The Bridgetown plant services about one eighth of the capital and its immediate environment with approximately one thousand five hundred $(1,500)$ connections majority being commercial. The average daily flow rate for the Bridgetown and South Coast sewage systems are 2.75 millions of gallons per day (mgd) and $0.85 \mathrm{mgd}$ respectively. The higher concentrations of caffeine found in the influent at the South Coast STP than the Bridgetown STP may be as a result of the former receiving a greater volume of waste daily and/or the population (including tourists) on the South Coast of Barbados are consuming higher volumes of caffeinated products (e.g. coffee). It is important to note, the South Coast STP is located in the Christ Church parish that has numerous hotels and night clubs and as a result the volume of raw sewage being carried to this treatment plant might be much greater than the raw sewage being carried to the Bridgetown plant daily. Furthermore, sampling was conducted at the beginning (December) of the tourist season. Generally during the month of December there is a vast increase in numbers of stay over visitors in Barbados.

The caffeine profile diagram (Figure 3) above shows that secondary and tertiary wastewater treatments are very effective in eliminating caffeine. According to Figure 3 below, advance (tertiary) treatment plants consisting of biological treatment (e.g. activated sludge and biological reactor processes) along with chlorination or ozonation produced caffeine-removing efficiencies of 98-100\% (Yang et al. 2011; Trenholm et al. 2006; Karnjanapiboonwong et al. 2011). Secondary treatment plants that employed primary treatment along with biological treatment produced caffeine-removing efficiencies of 70-96\% (Sim et al. 2011; Tewari et al. 2013, Behera et al. 2011; Martín et al. 2012). In Canada, primary sedimentary tanks were ineffective in eliminating caffeine resulting in $<10 \%$ removal efficiency (Boisvert et al. 2012). 
The caffeine removal efficiency results in this study were consistent with that of the literature as the secondary treatment plant (99\%) was very effective in eliminating caffeine. However, the primary treatment plant (38\%) was less effective in destroying caffeine. There is a paucity of data related to caffeine removal in primary treatment systems. Thus, in relation to the research conducted in Canada by Boisvert et al. 2012 the primary treatment plant in Barbados was found to be more effective in eliminating caffeine. Aeration of the raw sewage at the primary treatment plant in Barbados may have allowed for some aerobic microbial decomposition of caffeine or due to some adsorption of caffeine to sludge particles. Other significant factors such as residence time, flow rate and sludge age must also be considered. Several researchers maintained that wastewater treatment plants elimination of caffeine (81-100\%) have been found to be most effective when secondary treatment (e.g. biological treatment) is employed (Buerge et al. 2006; Lin et al. 2009; Siegener and Chen 2002; Benotti and Brownawell 2007).

In Barbados the treated wastewater is deposited far out at sea. The U.S. FDA recommended a 10-fold dilution factor to predict the concentrations of drugs in surface waters from estimated concentrations in STP effluents
(United States Federal Drug Administration 1998). Moreover, researchers have found that this dilution factor is representative of effluent discharges into natural water (Metcalfe et al. 2003; Dorn 1996). Future research on caffeine in marine environment in Barbados will determine if the FDA 10-fold dilution factor is representative of caffeine concentrations in STP effluents deposited at sea.

\section{Caffeine decomposition in aqueous solutions \\ Acidic and neutral media}

Concentration of caffeine in pure water and $0.01 \mathrm{~mol} \mathrm{~L}^{-1}$ $\mathrm{HCl}$ aqueous solutions did not show any evidence of decomposition after boiling at $100^{\circ} \mathrm{C}$ under reflux for 8 hours. The stability of caffeine at acidic and neutral $\mathrm{pH}$ may be due to its aromaticity. Caffeine is a two member ring structure consisting of amides, amines and alkenes functional groups. The five-membered ring in the caffeine molecule is aromatic as it is cyclic and planar. Furthermore, the $\mathrm{N}-\mathrm{CH}_{3}$ nitrogens have a lone pair located in the p-orbital that can participate in delocalization and resonance which increase the stability of the molecule. According to Boisvert et al. 2012, caffeine is in its protonated form at $\mathrm{pH}$ conditions below its pka of 10.4. At alkaline conditions greater than
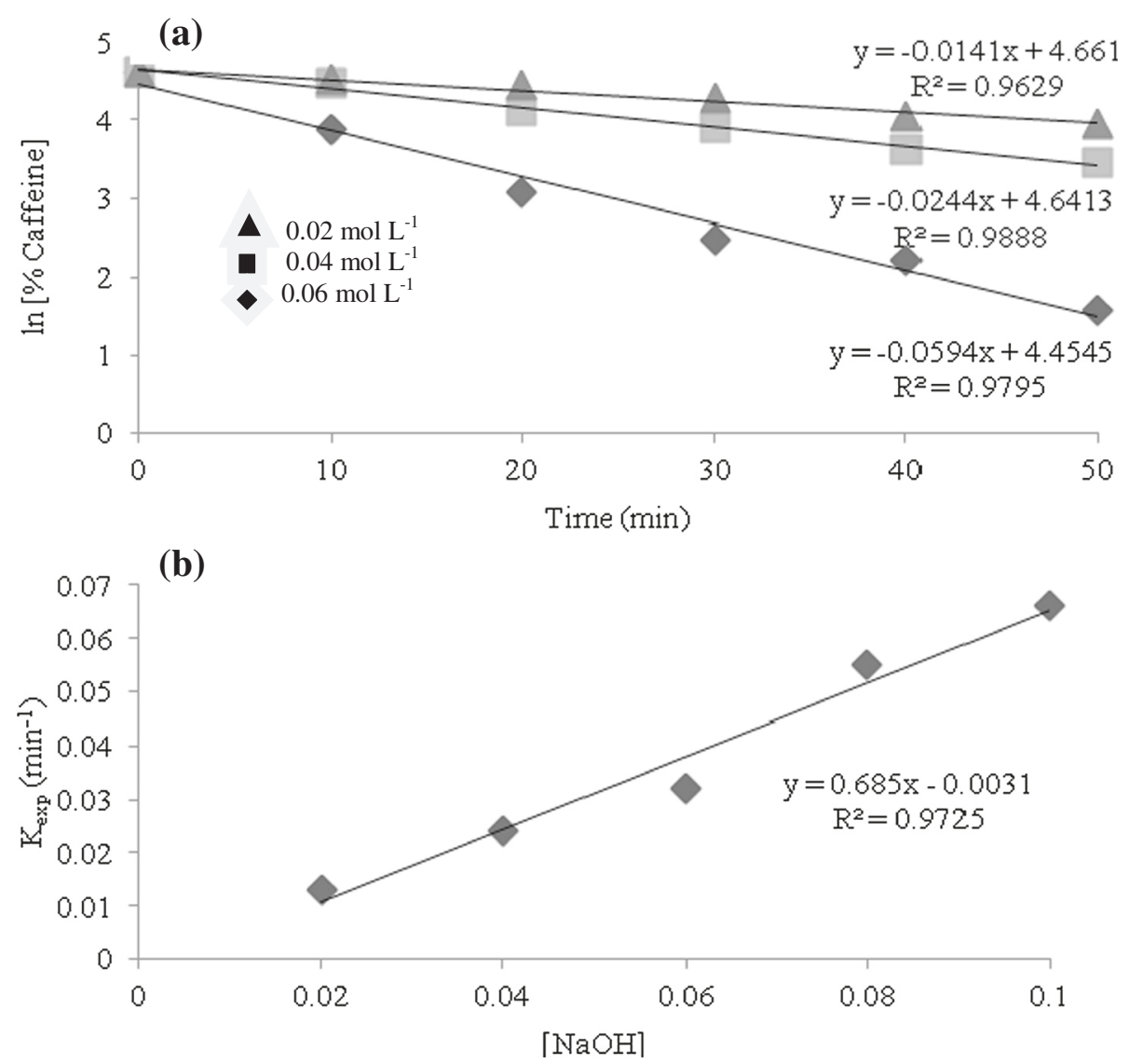

Figure 4 Effects of different $\mathrm{NaOH}$ concentrations on (a) caffeine degradation at $100^{\circ} \mathrm{C}$ and (b) the overall rate of degradation. 
Table 4 Rate constants and half-lives for the destruction of caffeine in solutions of varying $[\mathrm{OH}]$ at $100^{\circ} \mathrm{C}$

\begin{tabular}{lll}
\hline$[\mathrm{NaOH}] \mathbf{~ m o l ~ L}^{-\mathbf{1}}$ & $\mathbf{k}_{\exp }\left(\mathbf{m i n}^{-\mathbf{1}}\right)$ & Half-life $(\mathbf{m i n})$ \\
\hline 0.02 & 0.014 & 49.5 \\
0.04 & 0.024 & 28.9 \\
0.06 & 0.052 & 13.3 \\
0.08 & 0.059 & 11.7 \\
0.1 & 0.066 & 10.5 \\
\hline
\end{tabular}

$\mathrm{pH} 10.4$, the molecule is found in its neutral form. Researchers have maintained that the protonated form is more water soluble and less volatile than the neutral, unprotonated form (Boisvert et al. 2012; Bahrami et al. 2013). Therefore, it may be impossible to study the stability of caffeine to hydrolysis at conditions close to the natural environment in Barbados (neutral solutions and temperatures $26-30^{\circ} \mathrm{C}$ ). However, caffeine in $0.01 \mathrm{~mol} \mathrm{~L}^{-1}$ $\mathrm{NaOH}$ slowly degraded at $100^{\circ} \mathrm{C}$. This proved that base catalyzed reaction kinetics could be studied at elevated $\mathrm{NaOH}$ concentrations. Furthermore, the results can be extrapolated to fit normal temperatures and variable $\mathrm{pH}$.

\section{Basic solutions}

Experimental data shows that the rate of caffeine disappearance is first order with respect to concentration of both caffeine and $\mathrm{OH}^{-}$. The second order rate constant at $100^{\circ} \mathrm{C}$ was found to be $0.71 \pm 0.10 \mathrm{~mol} \mathrm{~L}^{-1} \mathrm{~min}^{-1}$. This shows that we can estimate the rate constant and half-life of caffeine destruction at moderate $\mathrm{pH}$ and temperature with reasonable accuracy.

$$
\begin{aligned}
& \frac{-\mathrm{d}[\text { Caffeine }]}{\mathrm{dt}}=\mathrm{k}_{2}[\text { Caffeine }]\left[\mathrm{OH}^{-}\right] \\
& \mathrm{k}_{1(\exp )}=\left[\mathrm{OH}^{-}\right] \times \mathrm{k}_{2}
\end{aligned}
$$

At constant $\mathrm{NaOH}$ concentration, pseudo-first order rate constant $k_{\exp }=\mathrm{k}\left[\mathrm{OH}^{-}\right]$can be calculated from the integrated rate equation:
Table 5 Calculated rate constants and half-lifes for the disappearance of caffeine in water at $30^{\circ} \mathrm{C}$, extrapolated from experimental data

\begin{tabular}{lll}
\hline $\mathbf{p H}$ & $\mathbf{k}\left(\mathbf{m i n}^{-1}\right)$ & Half-life (Years) \\
\hline 6 & $6.6 \times 10^{-11}$ & $2.0 \times 10^{4}$ \\
7 & $6.6 \times 10^{-10}$ & $2.0 \times 10^{3}$ \\
8 & $6.6 \times 10^{-9}$ & $2.0 \times 10^{2}$ \\
9 & $6.6 \times 10^{-8}$ & $2.0 \times 10^{1}$ \\
\hline
\end{tabular}

$$
\ln [\text { Caffeine }]=-k_{\text {exp }} \mathrm{t}+\text { constant }
$$

In correspondence with equation 3, Figure 4 illustrates the kinetics of caffeine disappearance in the range of basic concentrations investigated. The experimental rate constants and half-lives at $100^{\circ} \mathrm{C}$ are presented in Table 4.

The data shows that caffeine should be destroyed (whether decomposed, transformed or mineralized) within minutes to hours when subjected to strong alkaline conditions and elevated temperatures. However, even more interesting is its estimated rate of degradation at conditions close to the natural environment in the Caribbean region. Using the Arrhenius plot (Figure 5), Arrhenius equation was used to determine the rate of caffeine degradation at $30^{\circ} \mathrm{C}$. The results are reported in Table 5.

Calculations show that caffeine should be practically stable indefinitely in aqueous solutions at moderate temperature and $\mathrm{pH}$. Environmental water in Barbados (Caribbean region) is generally of $\mathrm{pH} 6-8$. Notably, this estimation does not take into account biological degradation, dilution, sorption or ultraviolent radiation (UV). These other means of caffeine destruction or chemical transformation in the environment are important, however, researchers emphasized that partitioning (sedimentation and volatilization) and photodegradation have negligible effects on caffeine in surface waters. Biodegradation is probably the principal means of caffeine

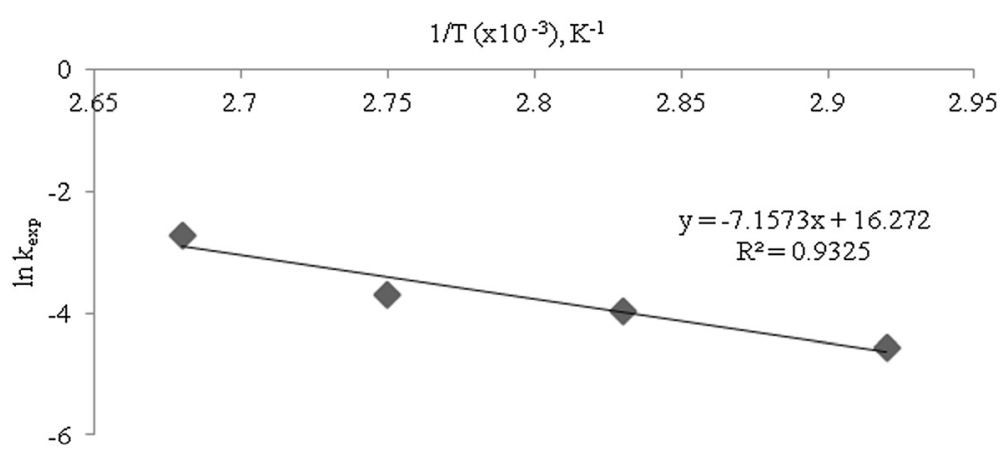

Figure 5 Arrhenius plot for decomposition of caffeine; Ea $=59.5 \mathrm{~kJ} \mathrm{~mol}^{-1}$ and $A=1.2 \times 10^{7} \mathrm{~min}^{-1}$. 


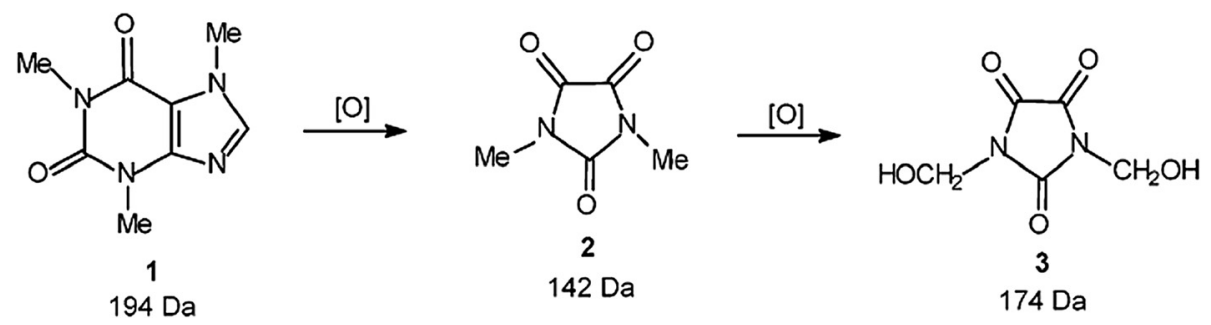

Figure 6 Caffeine and its oxidative by-products (Dalmázio et al. 2005).

removal from surface waters (Buerge et al. 2003; Buerge et al. 2006).

The stability of caffeine at moderate temperature and $\mathrm{pH}$ is in agreement with Buerge et al. 2006 who concluded that caffeine degrades slowly (half-life of about 10 years). However, we have found its half-life between 20-20,000 years depending on the $\mathrm{pH}$ of water.

Dalmázio et al. 2005, emphasized that caffeine (194 Da) degradation is likely to generate persistent intermediates that may not be as efficiently oxidized as caffeine. In their work they highlighted two major degradation products (N- dimethylparabanic acid, $142 \mathrm{Da}$, and di(N-hydroxymethyl) parabanic acid, 174 Da) generated by advanced oxidative conditions. Furthermore, the researchers showed the importance of the hydroxyl radical in caffeine destruction or transformation leading to slow mineralization. Caffeine is oxidized by hydroxyl radicals in water as shown in Figure 6.

Other studies have identified other caffeine intermediates via demethylation, hydrolysis and hydroxylation. These included 1,3,7-trimethyluric acid, theophyline, 1,3-dimethyluric acid and 6-amino-5-( $N$-formylmethylamino)-1,3-dimethyl-uracil (Telo and Vieira 1997; Stadler et al. 1996).

The results of this study corroborate the recalcitrance of caffeine to hydrolytic degradation in water of moderate temperature and $\mathrm{pH}$. Thus, caffeine disappearance (whether transformation or mineralization) in the environmental water may be due to other processes such as biodegradation, dilution, sorption and solar destruction.

\section{Conclusions}

The developed SPE method was successful in extracting caffeine from environmental water. GC-MS/MS-MRM was effective as a quantification method for caffeine in water samples at ng $\mathrm{L}^{-1}$ concentrations. The study has identified caffeine in all surface water sites investigated and has highlighted one specific site in the capital city having caffeine concentration above those found in EU and U.S. surface waters. Caffeine levels in surface water are primarily attributed to anthropogenic sources (caffeinated products) as caffeine-producing plants are rare in Barbados. Caffeine was found in higher concentrations at the South Coast WTTP than the Bridgetown WWTP. However, the latter (secondary treatment plant) was more effective in eliminating caffeine than the former (primary treatment plant). The caffeine concentrations in raw sewage and treated sewage are similar to samples collected elsewhere. All surface water sites and treated wastewater are disposed at sea.

Little is known about the effects of caffeine in the marine waters; however, some studies have cautioned that caffeine in the seawater may exacerbate the effects of other environmental factors that aid in coral bleaching. This study has found caffeine to be practically stable indefinitely in aqueous solutions thus its destruction in the environment is due to other processes. Currently, the Caribbean region does not have established standards or health advisories for caffeine and pharmaceuticals in natural waters. Thus, more research on caffeine as a potential chemical indicator of domestic wastewater may become an important issue because of its clear anthropogenic origin and ubiquitous detection in surface and wastewaters.

\section{Competing interests}

The authors declare that they have no competing interests.

\section{Authors' contributions}

All three authors (QE, SK and LG) were equally involved in the design and execution of the conducted research (project conception, research planning, laboratory experimentation and data collection). QE, SK and LG were significantly involved in statistical analysis, manuscript drafting and editing. All authors have given final approval of the manuscript and acknowledge their accountability of the contents of the paper.

\section{Acknowledgements}

This work was supported by the University of the West Indies, Cave Hill Campus, Barbados. We gratefully acknowledge the Barbados Water Authority and Environmental Protection Department for assisting with water sampling (more specifically Mr. Gregory Thompson and Mr. Anthony Headley). Also, we must show appreciation to Prof. Marc Lavoie, laboratory staff, technicians and graduate students at the University of the West Indies for making this research project successful.

Received: 29 August 2014 Accepted: 12 January 2015

Published online: 03 February 2015 


\section{References}

Asano Y, Komeda T, Yamada H (1993) Microbial production of theobromine from caffeine. Biosci Biotechnol Biochem 57(8):1286-1289

Bahlmann A, Carvalho JJ, Weller MG, Panne U, Schneider RJ (2012) Immunoassays as high-throughput tools: Monitoring spatial and temporal variations of carbamazepine, caffeine and cetirizine in surface and wastewaters. Chemosphere 89(11):1278-1286

Bahrami H, Tabrizchi M, Farrokhpour H (2013) Protonation of caffeine: A theoretical and experimental study. Chem Phys 415:222-227

Behera SK, Kim HW, Oh JE, Park HS (2011) Occurrence and removal of antibiotics, hormones and several other pharmaceuticals in wastewater treatment plants of the largest industrial city of Korea. Sci Total Environ 409(20):4351-4360

Beltrán JG, Leask RL, Brown WA (2006) Activity and stability of caffeine demethylases found in Pseudomonas putida IF-3. Biochem Eng J 31(1):8-13

Benotti MJ, Brownawell BJ (2007) Distributions of pharmaceuticals in an urban estuary during both dry- and wet-weather conditions. Environ Sci Technol 41(16):5795-5802

Berthou F, Guillois B, Richie C, Dreano Y, Jacqz-Aigrain E, Beaune P (1992) Interspecies variations in caffeine metabolism related to cytochrome P4501A enzymes. Xenobiotica 22(6):671-680

Boisvert M, Fayad PB, Sauvé S (2012) Development of a new multi-residue laser diode thermal desorption atmospheric pressure chemical ionization tandem mass spectrometry method for the detection and quantification of pesticides and pharmaceuticals in wastewater samples. Anal Chim Acta 754:75-82

Buerge IJ, Poiger T, Muller MD, Buser HR (2003) Caffeine, an anthropogenic marker for wastewater contamination of surface waters. Environ Sci Technol 37(4):691-700

Buerge IJ, Poigner T, Müller MD, Muser HR (2006) Combined sewer overflow to surface waters detected by the anthropogenic marker caffeine. Environ Sci Technol 40(13):4096-4102

Chen H, Li XJ, Zhu SC (2012) Occurrence and distribution of selected pharmaceuticals and personal care products in aquatic environments: a comparative study of regions in China with different urbanization levels. Environ Sci Pollut Res 19(6):2381-2389

Comeau F, Surette C, Brun GL, Losier R (2008) The occurrence of acidic drugs and caffeine in sewage effluents and receiving waters from three coastal watersheds in Atlantic Canada. Sci Total Environ 396(2-3):132-146

Dalmázio I, Santos LS, Lopes RP, Eberlin MN, Aususti R (2005) Advanced oxidation of caffeine in water: Online and real-time monitoring by electrospray ionization mass spectroscopy. Environ Sci Technol 39:5982-5988

Dash SS, Gummadi SN (2006) Biodegradation of caffeine by Pseudomonas Sp. Using response surface methodology. Biochem Eng J 36:288-293

Dash SS, Gummadi SN (2007) Enhanced biodegradation of caffeine by Pseudomonas sp. using response surface methodology. Biochem Eng J 36(3):288-293

Dorn PB (1996) An industrial perspective on whole effluent toxicity testing. In: Groth DR, Dickson KL, Reed-Judkins LH (eds) Whole Effluent Toxicity Testing: An Evaluation of Methods and Prediction of Receiving System Impacts. Society for Environmental Toxicology and Chemistry (SETAC), Pensacola, FL, USA, pp 34-47

Ferreira AP (2005) Caffeine as an environmental indicator for assessing urban aquatic ecosystem. Cad Saude Publica 21(6):1884-1892

Froehner S, Martins RF (2008) Evaluation of the chemical composition of sediments from the Barigüi River in Curitiba, Brazil. Quim Nova 3(8):2020-2026

Froehner S, Souza DB, Machado KS, da RE C (2010) Tracking Anthropogenic inputs in Barigui River, Brazil Using Biomarkers. Water Air Soil Pollut 210:33-41

Gokulakrishnan S, Chandraraj K, Gummadi SN (2005) Microbial and enzymatic methods for the removal of caffeine. Enz MicroTechnol 37(2):225-232

Gómez MJ, Martínez Bueno MJ, Lacorte S, Fernández-Alba AR, Agüera A (2007) Pilot survey monitoring pharmaceuticals and related compounds in sewage treatment plant located on the Mediterranean coast. Chemosphere 66(6):993-1002

Karnjanapiboonwong A, Suski JG, Shah AA, Cai QS, Morse AN, Anderson TA (2011) Occurrence of PPCPs at a wastewater treatment plant and in soil and groundwater at a land application site. Water Air Soil Pollut 216(1-4):257-273

Knee KL, Gossett R, Boehm AB, Paytan A (2010) Caffeine and agriculture pesticides concentrations in surface water and groundwater on the North Shore of Kauai (Hawaii, USA). Mar Pollut Bull 60(8):1376-1382
Kurissery S, Kanavillil N, Verenitch S, Mazumder A (2012) Caffeine as an anthropogenic marker of domestic waste: A study from Lake Simcoe watershed. Ecol Indic 23:501-508

Li H, Helm PA, Metcalfe CD (2010) Sampling in the Great Lakes for pharmaceuticals, personal care products and endocrine-disrupting substances using the passive polar organic chemical integrative sampler. Environ Toxicol Chem 9999(12):1-12

Lin AYC, Yu TH, Lateef SK (2009) Removal of pharmaceuticals in secondary wastewater treatment processes in Taiwan. J Hazard Mater 167(1-3):1163-1169

Martín J, Camacho-Muñoz D, Santos JL, Aparicio I, Alonso E (2012) Occurrence of pharmaceutical compounds in wastewater and sludge from wastewater treatment plants: Removal and ecotoxicological impact of wastewater discharges and sludge disposal. J Hazard Mater 239-240:40-47

Metcalfe CD, Miao XS, Koenig BG, Struger J (2003) Distribution of acidic and neutral drugs in surface waters near sewage treatment plants in the lower Great Lake, Canada. Environ Toxicol Chem 22(12):2881-2889

O'Brien E, Dietrich DR (2004) Hindsight rather than foresight: reality versus the EU draft guideline on pharmaceuticals in the environment. Trends Biotechnol 22(7):326-330

Peeler KA, Opsahl SP, Chanton JP (2006) Tracking anthropogenic inputs using caffeine, indicator bacteria, and nutrients in rural freshwater and urban marine systems. Environ Sci Technol 40(24):7616-7622

Pollack K, Balazs K, Ogunseitan O (2009) Proteomic assessment of caffeine effects on coral symbionts. Environ Sci Technol 43(6):2085-2091

Rodriguez del Rey Z, Granek EF, Sylvester S (2012) Occurrence and concentration of caffeine in Oregon coastal waters. Mar Pollut Bull 64(7):1417-1424

Rounds SA, Doyle MC, Edwards PM, Furlong ET (2009) Reconnaissance of pharmaceutical chemicals in urban streams of the Tualatin River basin, Oregon, 2002. In: US Geological Survey Scientific Investigations Report 20095119. US Government Printing Office, Washington, DC, p 22, http://pubs.usgs. gov/sir/2009/5119/pdf/sir20095119.pdf. Accessed 18 July, 2013

Seiler RL, Steven ZD, Thomas JM, Howcroft DL (1999) Caffeine and pharmaceuticals as indicators of waste water contamination in wells. Ground Water 37(3):405-410

Shalmashi A, Golmohammad F (2010) Solubility of caffeine in water, ethyl acetate, ethanol, carbon tetrachloride, methanol, chloroform, dichloromethane and acetone between $298 \mathrm{~K}$ and $323 \mathrm{~K}$. Lat Am Appl Res 40(3):327-341

Siegener R, Chen RF (2002) Caffeine in Boston Harbor Seawater. Mar Pollut Bull 44(5):383-387

Sim WJ, Lee JW, Lee ES, Shin SK, Hwang SR, Oh JE (2011) Occurrence and distribution of pharmaceuticals in wastewater from households, livestock farms, hospitals and pharmaceutical manufactures. Chemosphere 82(2):179-186

Singh S, Azua A, Chaudhary A, Khan S, Willett K, Gardinali P (2010) Occurrence and distribution of steroids, hormones and selected pharmaceuticals in South Florida coastal environments. Ecotoxicol 19(2):338-350

Stadler RH, Richoz J, Turezki RJ, Welti DH, Fay LB (1996) Oxidation of caffeine and related methylxanthines in ascorbate and polyphenol-driven fenton-type oxidations. Free Radic Res 24:225-240

Standley LJ, Kaplan LA, Smith D (2002) Molecular tracers of organic matter sources to surface water resources. Environ Sci Technol 34(15):3124-3130

Telo JP, Vieira AJSC (1997) Mechanism of free-radical oxidation of caffeine in aqueous solution. J Chem Soc Perkin Trans 2:1755-1758

Tewari S, Jindal R, Kho YL, Eo S, Choi K (2013) Major pharmaceutical residues in wastewater treatment plants and receiving waters in Bangkok, Thailand, and associated ecological risks. Chemosphere 91(5):697-704

Thomas PM, Foster GD (2005) Tracking acidic pharmaceuticals, caffeine, and triclosan through the wastewater treatment process. Environ Toxicol Chem 24(1):25-30

Trenholm RA, Vanderford BJ, Holady JC, Rexing DJ, Snyder SA (2006) Broad range analysis of endocrine disruptors and pharmaceuticals using gas chromatography and liquid chromatography tandem mass spectrometry. Chemosphere 65(11):1990-1998

United States Federal Drug Administration (1998) Guidance for industryenvironmental assessment of human drugs and biologics applications, Revision 1. Centre for Drug Evaluation and Research, Rockville, MD, USA

Verenitch SS, Mazumder A (2008) Development of a methodology utilizing gas chromatography ion-trap tandem mass spectrometry for the determination of low levels of caffeine in surface marine and freshwater samples. Anal Bioanal Chem 391(7):2635-2646 
Wu J, Yue J, Hu R, Yang Z, Zhang L (2010) Use of caffeine and human pharmaceutical compounds to identify sewage contamination. Int J Civ Environ Eng 2(2):98-102

Yamaoka-Yano DM, Mazzafera P (1999) Catabolism of caffeine and purification of a xanthine oxidase responsible for methyluric acids production in Pseudomonas putida L. Rev Microbiol 30(1):62-70

Yang X, Flower RC, Weinberg HS, Singer PC (2011) Occurrence and removal of pharmaceuticals and personal care products (PPCPs) in an advanced wastewater reclamation plant. Water Res 45(16):5218-5228

Yargeau V, Lopata A, Metcalfe CD (2007) Pharmaceuticals in the Yamaska River, Quebec, Canada. Water Qual Res Can 42(4):231-239

Yu CL, Louie TM, Summers R, Kale Y, Gopishetty S, Mani Subramanian S (2009) Two distinct pathways for metabolism of theophylline and caffeine are coexpressed in Pseudomonas putida CBB5. Am Soc Microbiol 191(14):4624-4632

Submit your manuscript to a SpringerOpen ${ }^{\odot}$ journal and benefit from:

- Convenient online submission

- Rigorous peer review

- Immediate publication on acceptance

- Open access: articles freely available online

- High visibility within the field

- Retaining the copyright to your article

Submit your next manuscript at $\gg$ springeropen.com 